\title{
Evaluation of a FO-PID Controller in a Buck DC/DC Converter Model
}

\section{Evaluación de un controlador FO-PID en un modelo de convertidor Buck DC / DC}

\author{
MUNOZ-HERNANDEZ, German A.*†, DAMIAN-MORA, Ana S., RAMIREZ-ESPINOZA, Jose and \\ CHAVEZ-GALAN, Jesus
}

Instituto Tecnológico de Puebla / Tecnologico Nacional de Mexico

ID $1^{\text {st }}$ Author: German A, Munoz-Hernandez / ORC ID: 0000-0003-4861-0345, CVU CONACYT ID: 122490

ID $1^{\text {st }}$ Coauthor: Ana S., Damian-Mora / ORC ID: 0000-0002-6199-3304, CVU CONACYT ID: 798885

ID $2^{\text {nd }}$ Coauthor: Jose, Ramirez-Espinoza / ORC ID: 0000-0002-7313-9770, CVU CONACYT ID: 950645

ID $3^{\text {rd }}$ Coauthor: Jesus, Chavez-Galan / CVU CONACYT ID: 98742

DOI: $10.35429 /$ JSTA.2019.15.5.1.8

Received: March 20, 2019; Accepted: May 29, 2019

\begin{abstract}
The applications of electrical energy converters are wide. It is a common device that can be found in almost every apparatus, both industrial and domestic. This work will deal with linear and nonlinear models of DC/DC converters. Those models will used to probe, by simulation, classic and advance controllers. PID controllers have shown a good response regulating DC/DC converters, for that reason the inclusion of two more degree of freedom due to the Integral and derivative of Fractional Order, could improve the performance of these controllers. Furthermore, Piecewise modeling can be useful to obtain adaptive controllers whose parameters change at different operational conditions.
\end{abstract}

DC/DC Converters, Piecewise modeling, Fractional-Order Controllers

\begin{abstract}
Resumen
Las aplicaciones de los convertidores de energía eléctrica son muy amplias. Es un dispositivo común que puede ser encontrado en casi cualquier equipo, tanto industrial como doméstico. Este trabajo emplea modelos lineales y no-lineales de convertidores $\mathrm{CD} / \mathrm{CD}$. Estos modelos son usados para probar, mediante simulación, controladores clásicos y avanzados. Los controladores PI han mostrado una buena respuesta en la regulación de convertidores $\mathrm{CD} / \mathrm{CD}$, por esta razón la inclusión de dos grados de libertad adicionales proporcionados por el control PID de orden fraccional, pudiera mejorar la respuesta de los mismos. Además, el modelado "a trozos" puede ser útil para obtener reguladores adaptativos donde los parámetros de control pueden cambiar debido a diferentes condiciones de operación.
\end{abstract}

Convertidores CD/CD, Modelado a trozos, Controladores de orden fraccional Applications. 2019. 5-15: 1-8.

\footnotetext{
* Correspondence to Author (gmunoz@ieee.org)

$\dagger$ Researcher contributing first Author.
} 


\section{Introduction}

To achieve an energy flow in DC/DC Converters, the switches must allow the current to flow in both directions. This energy flow is usually implemented with unidirectional semiconductor devices such as MOSFETs or IGBTs in parallel with a diode. This diode is usually implemented for the protection of the device, in case the current flows in the opposite direction to the expected one. In this work, we use a Buck converter with diode, Figure 1, with an inductor of $1 \mathrm{mH}$, a switching frequency of $250 \mathrm{KHz}$, a capacitance of $0.1 \mu \mathrm{Fd}$ and a $50 \Omega$ resistive load in parallel with the capacitor.

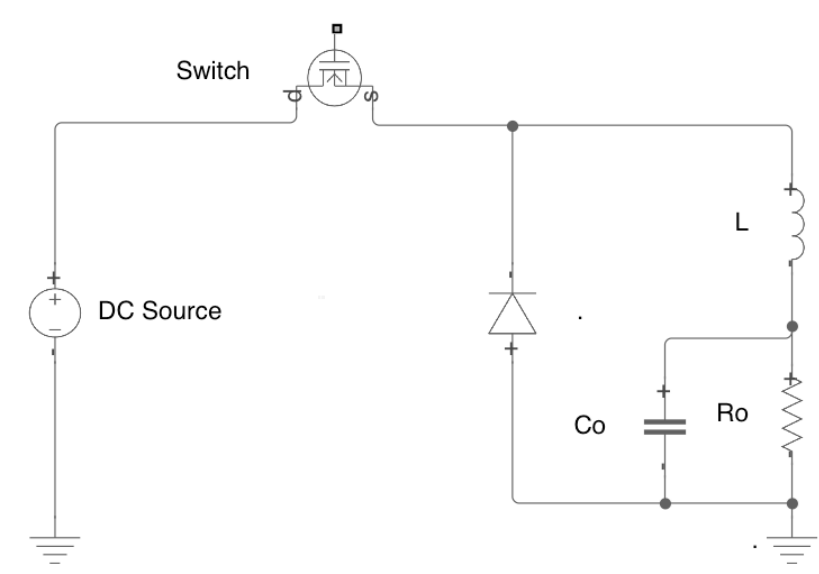

Figure 1 Buck converter circuit

\section{DC/DC Converters}

The model of regulation of DC-DC converters by interruption can be dated until the works of Middlebrook and Cuk, in the mid 70's of the last century. The area has grown enormously from there (Alternative Energy Institute \& Smith, 2005) (Kruger, 2006) (Hossain, Rahim, \& Selvaraj, 2018). DC-DC converters use one or more switches to transform DC power from one level to another. In a DC-DC converter with a given input voltage, regulating the switch times controls the average output voltage. PWM (Pulse Width Modulation) with a constant frequency is a common method to control the converters (Bacha, Munteanu, \& Bratcu, 2014).

For voltage control, comparing a reference with the voltage output signal level generates the control signal of the switch. The error will be used to generate a square signal that turns on or off the switches. The frequency is kept constant in a PWM control and is chosen within a few kilohertz to hundreds of kilohertz.

\section{DC/DC Converters configuration}

Based on the general description of the operation of the converters, some of the topologies will be briefly explained.

\section{Reducing converter (BUCK)}

The reducing converter produces a lower output voltage than the input Voltage. Assuming an ideal switch, a constant input voltage is applied to the circuit and the switch position determines if the load is energized or not. Then the average output voltage is calculated in terms of the working ratio of the switch. The average output voltage varies linearly with the control voltage, as is the case in linear amplifiers. In real applications, the antecedent circuit has two disadvantages: the load would be inductive, even with a resistive load; there would always be some inductance of dispersion. That means that the switch would have to absorb (or dissipate) the inductive energy and therefore could be damage.

The output voltage fluctuates between zero and the value of the input Voltage, which is not acceptable in most applications. The problem of the stored inductive energy is overcome by a diode, which upon opening the trigger device is reverse biased and the circuit allows the energy to flow through the charge. The fluctuations of the output voltage are greatly reduced when using a low-pass filter, which consists of an inductor and a capacitor. The frequency of angle of this low pass filter is selected to be much lower than the commutation frequency, to essentially eliminate the ripple or curl of the switching frequency in the output voltage (Alternative Energy Institute \& Smith, 2005) (Erickson \& Maksimovic, 2004).

\section{Lifting converter (BOOST)}

On these converters the output voltage is always larger than the input voltage. When the switch is on, the diode is reverse biased, which isolates the output stage, see Figure 2. The input supplies power to the inductor. When the switch is off, the output stage receives power from both the inductor and the input. 
In the analysis of the permanent state, it is assumed that the output filter capacitor is very large, in order to ensure a constant output voltage (Alternative Energy Institute \& Smith, 2005) (Erickson \& Maksimovic, 2004).



Figure 2 Boost converter circuit

\section{Reducing-lifting converter (BUCK-BOOST)}

A reducer-elevator converter is obtained by means of the cascade connection of the two basic converters: reducer and elevator. In permanent state, the conversion ratio of output voltage to input voltage is the product of the conversion ratios of the two cascaded converters (if the switches in both converters have the same working relationship); this allows the output voltage to be greater or less than the input voltage, based on the duty ratio (Figure 3). The cascade connection of the stepdown converters is combined in the individual step-down converter. When the switch is closed, the input feeds power to the inductor and the diode is in reverse bias. When the switch is open, the energy accumulated in the inductor is transferred to the output. During this interval, the inductor does not supply power (Alternative Energy Institute \& Smith, 2005) (Erickson \& Maksimovic, 2004).

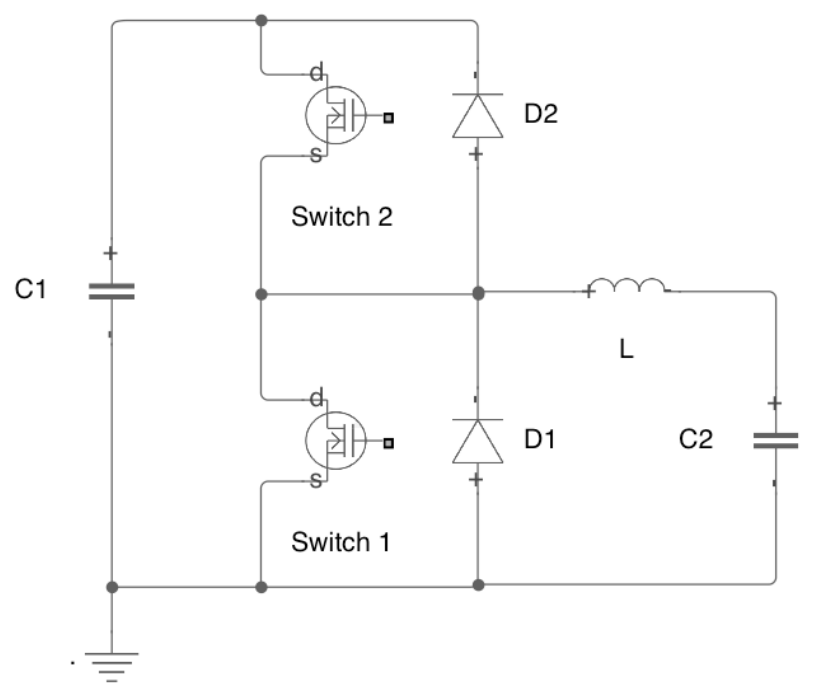

Figure 3 Buck-Boost converter circuit

\section{Modeling of DC/DC Converters}

Two Transfer Function, equations (1) and (2), are normally used to represent a DC/DC converter (Erickson \& Maksimovic, 2004). As can be seen the have two poles and also the equation (1) has one zero. The zero is located at the right-half of the S-Plane. That produces a non-minimum phase response. The equation (1) is called control-to-output transfer function. For its part, the equation (2) is called line-to-output transfer function.

$$
G_{v d}(S)=G_{d 0} \frac{1-\frac{S}{\omega_{2}}}{1+\frac{S}{Q \omega_{0}}+\left(\frac{S}{\omega_{0}}\right)^{2}}
$$

$$
G_{v g}(S)=G_{g 0} \frac{1}{1+\frac{S}{Q \omega_{0}}+\left(\frac{S}{\omega_{0}}\right)^{2}}
$$

Table 1 summarized the relevant features of the line-to-output and control-to-output transfer functions of the basic buck, boost, and buck-boost converters (Erickson \& Maksimovic, 2004).

In equations (1) and (2):

$\mathrm{G}_{\mathrm{d} 0}$ Control-to-output transfer function gain $\mathrm{G}_{\mathrm{g} 0}$ Line-to-output gain

$\omega_{0}$

$\omega_{\mathrm{z}}$

Also for Table 1 (see Figures 1 and 2):

D Duty Cycle

D' Duty Cycle minus 1

V Output Voltage

R Resistive Load

L Inductor value

C Capacitor Value

Q Converter Quality factor.

The converter quality factor is a measure of the dissipation in the system defined by:

$$
Q=2 \frac{\text { Peak_stored_energy }}{\text { Energy_dissipated_per_cycle }}=\frac{1}{2}
$$

where $\zeta$ is the damping factor. 


\begin{tabular}{ll|l|l|l|l|} 
Converter & $\mathrm{G}_{\mathrm{g} 0}$ & $\mathrm{G}_{\mathrm{d} 0}$ & $\omega_{0}$ & $\mathrm{Q}$ & $\omega_{\mathrm{z}}$ \\
\cline { 2 - 6 } $\begin{array}{l}\text { Buck } \\
\text { Boost }\end{array}$ & $\mathrm{D}$ & $\mathrm{V} / \mathrm{D}$ & $1 /(\mathrm{LC})^{1 / 2}$ & $\mathrm{R}(\mathrm{C} / \mathrm{L})^{1 / 2}$ & $\infty$ \\
\cline { 2 - 6 } & 1/D/D' & $\mathrm{D}^{\prime} /(\mathrm{LC})^{1 / 2}$ & $\mathrm{D}^{\prime} \mathrm{R}(\mathrm{C} / \mathrm{L})^{1 / 2}$ & $\left(\mathrm{D}^{\prime 2} \mathrm{R}\right) / \mathrm{L}$ \\
\hline
\end{tabular}

Table 1 Parameters of the DC/DC converter Transfer Functions (1) and (2)

\section{Piecewise Affine Modeling of DC/DC Converters}

The model of regulation of DC/DC converters by interruption can be dated until the works of Middlebrook and Cuk, in the mid 70's of the last century. The area has grown enormously from there (Alternative Energy Institute \& Smith, 2005) (Kruger, 2006). The DC/DC Converters are nonlinear systems, that means that their operation changes due to different parameters, among them operational point and frequency of operation. There are several methods to deal with those nonlinearities. In this work a hybrid systems approach will be discussed.

\section{Piecewise affine models of nonlinear systems}

Hybrid systems are used in large number of small-scale and industrial applications. They can be seemed as hierarchical schemes composed of dynamical components at the lower level, which are managed by discrete/logical components at the higher level (Bemporad \& Morari, 1999) (Witsenhausen, 1966) (Gollu \& Varaiya, 1989). Conventionally, there are two archetypes to conceptualize hybrid systems: aggregation and continuation. Nevertheless unified frameworks have appeared recently (Bemporad \& Morari, 1999) (Branicky, Borkar, \& Mitter, 1998).

The aggregation paradigm handles the entire system as a finite automaton or discreteevent dynamic system. It is usual in this method to divide the continuous state space and consider only the aggregate dynamics from group to group in the subset. The continuous paradigm handles the whole system as a differential equation. This can be done by two techniques: Simulating the discrete actions by means of nonlinear ordinary differential equations or handling the discrete actions as disturbances of the differential equations that represent the system.
The unified frameworks, aim to capture both discrete and continuous features to allow the designer free movement between analogue and discrete domains (Bemporad \& Morari, 1999) (Branicky, Borkar, \& Mitter, 1998). Piecewise affine systems are a potent method to approximate numerous nonlinear systems via multiple linearization at different operating points. In other words, many linear models are used, one by one depending on some operational conditions, to match a nonlinear system.

\section{Piecewise Affine Model of a DC/DC Buck Converter}

To illustrate the characteristics of a Piecewise Affine Model (PWAM); let us consider a simple linearized model of a DC/DC Buck converter. As was explained before two transfer-functions, (1) and (2), can be used to model the DC/DC converter operation. Besides, the "exact" model depends on the value of its parameters. Then, piecewise affine modeling approach is a good candidate to model the Buck converter.

Let us consider the buck converter (Figure 1), with $\mathrm{L}=1 \mathrm{mH}, \mathrm{C}_{0}=0.1 \mu \mathrm{fd}$ and $\mathrm{R}_{0}=50 \Omega$, at a switching frequency $\left(\mathrm{f}_{\mathrm{s}}\right)$ of 250 $\mathrm{KHz}$. If $\mathrm{G}_{\mathrm{d} 0}$ is considered negligent then $\mathrm{G}_{\mathrm{vd}}$ will be zero (1) and the output of the converter can be determined only by (2). As an example the working cycle $\left(\mathrm{W}_{\mathrm{c}}\right)$ will take the values of $10 \%$ and $50 \%$; whereas the DC input voltage $\left(\mathrm{V}_{\mathrm{i}}\right)$ will take the values of 5 and 8 volts. Because of that, a "static" equation will be only accurate in one group of values. However a PWAM will be accurate for all parameter combination. Eq. (4) determines the output signal for the Buck converter with the values stated before. As can be seen $G_{g o}$ is not constant, its value depends on $\mathrm{W}_{\mathrm{c}}$ and $\mathrm{V}_{\mathrm{i}}$.

$V_{o}(S)=G_{g 0} \frac{V_{i}(S)\left(1 \times 10^{10}\right)}{S^{2}+2 \times 10^{5} S+1 \times 10^{10}}$

The following integer values are defined:

$$
\begin{aligned}
& p_{1}=\left\{\begin{array}{lll}
0 & \text { if } & W_{c}=0.1 \\
1 & \text { if } & W_{c}=0.5
\end{array}\right. \\
& p_{2}=\left\{\begin{array}{lll}
0 & \text { if } & V_{i}=5 \\
1 & \text { if } & V_{i}=8
\end{array}\right.
\end{aligned}
$$


then the conditional integer values are also defined:

$$
\begin{array}{lllll}
{ }_{1}=1 & \text { if } & p_{1}=0 & p_{2}=0 & \left(G_{g 0}=0.0194\right) \\
{ }_{2}=1 & \text { if } & p_{1}=0 & p_{2}=1 & \left(G_{g 0}=0.0442\right) \\
{ }_{3}=1 & \text { if } & p_{1}=1 & p_{2}=0 & \left(G_{g 0}=0.4368\right) \\
{ }_{4}=1 & \text { if } & p_{1}=1 & p_{2}=1 & \left(G_{g 0}=0.4578\right)
\end{array}
$$

they follow the condition:

$$
\bigoplus_{i=1}^{4}[i=1]
$$

The output of the converter is then calculated by adding the four equations, each one multiplied by $\delta_{\mathrm{i}}(8)$.

$$
V_{o}(S)={ }_{1} V_{o, 1}(S)+{ }_{2} V_{o, 2}(S)+{ }_{3} V_{o, 3}(S)+{ }_{4} V_{o, 4}(S)
$$

that means that only one equation is working at any time.

A Matlab Simulink S-function was developed in order to simulate the PWAM and it was compared with the simulation of the electrical circuit. For this S-function, the user must supplied $\mathrm{W}_{\mathrm{c}}$ and $\mathrm{V}_{\mathrm{i}}$. Consider a simulation with $\mathrm{W}_{\mathrm{c}}=0.1$ and $\mathrm{V}_{\mathrm{i}}=5 \quad\left(\delta_{1}=1\right)$, after the initial conditions have been set, $\mathrm{Vi}$ is changed to 0.8 $\left(\delta_{2}=1\right)$ at $\mathrm{t}=0.0005 \mathrm{~s}$ of simulation. Then $\mathrm{V}_{\mathrm{i}}$ is changed again to $5\left(\delta_{1}=1\right)$ at $\mathrm{t}=0.001 \mathrm{~s}$ of simulation. As can be seen in Figure 4, the output signal from the electrical circuit simulated is close to the output signal from the PWAM. Refining $G_{g o}$ could reduce the difference between the two responses.

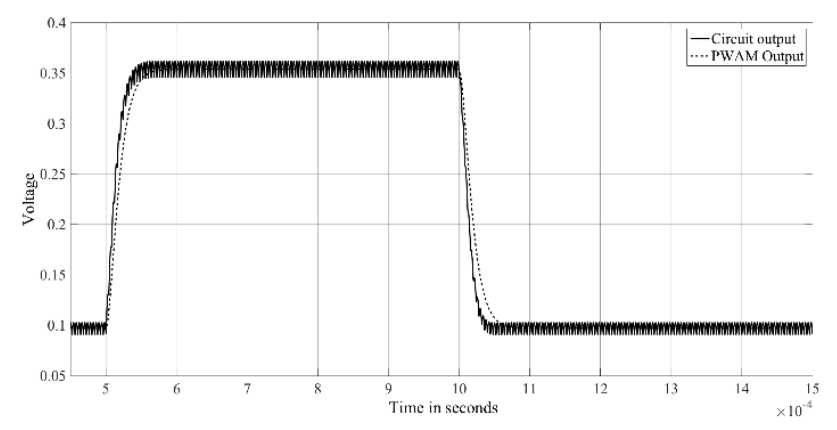

Figure 4 DC/DC Buck converter circuit vs PWAM under a $0.25 \mathrm{~V}$ step

Now consider a simulation with $\mathrm{W}_{\mathrm{c}}=0.5$ and $\mathrm{V}_{\mathrm{i}}=5 \quad\left(\delta_{3}=1\right)$, after the initial conditions have been set, $\mathrm{V}_{\mathrm{i}}$ is changed to $0.8\left(\delta_{4}=1\right)$ at $\mathrm{t}=0.0025 \mathrm{~s}$ of simulation, then $\mathrm{V}_{\mathrm{i}}$ is changed again to $5\left(\delta_{3}=1\right)$ at $\mathrm{t}=0.003 \mathrm{~s}$ of simulation.
As can be seen in Figure 5, the output signal from the circuit simulated in Simulink is virtually equal to the output signal from the PWAM. In this case the value of $\mathrm{Gg}_{\mathrm{go}}$ was selected to produce an output very close to the one from the circuit.



Figure 5 DC/DC Buck converter circuit vs PWAM under a $1.4 \mathrm{~V}$ step

\section{PI Control of DC/DC buck Converter}

\section{PID Controllers}

The Proportional (P), Integral (I) and Derivative (D) actions are usual modes of control. The controllers that comprise these actions are simple and robust; these features make them suitable for manual and automatic tuning. Equation (9) shows the PID controller in the classical form. The "power" parameters, $K_{p}, T_{i}$ and $T_{d}$, are selected depending on the contribution effort of each part. $\mathrm{K}_{\mathrm{p}}$ is used to modify the proportion of the error to be considered, $\mathrm{K}_{\mathrm{i}}$ for the integral of the error and $\mathrm{T}_{\mathrm{d}}$ for the derivate of the error.

Remember that $\mathrm{e}(\mathrm{t})$ (error signal) is the difference between the process reference and the output signal of the system to be controlled.

$$
u(t)=K_{p}\left(e(t)+\frac{1}{T_{i}} \int e(t) d t+T_{d} \frac{d e(t)}{d t}\right)
$$

PID's are widely used in DC/DC converters. However, as the output of the converter normally has ripples, it is common to suppress the derivative action. Then the controller is really a PI. To take into account the derivative action of the PID many approaches have been proved, one of them is to filter the error signal before its derivate is calculated. 


\section{Median Filter}

The median filter is habitually used to reduce noise in a signal. The algorithm of the filter, in this case of 1-D (vector), is described as follow. A time window is defined, with initial values of zero. The value of the input signal is aggregated to the vector, which is sorted form the lower value to the upper on, then the value that is in the middle of the vector is sending as the filter output. As the time passes, new values are aggregated to the vector, the newest replacing to the oldest. The process is repeated until the process stop. In this work, a median filter is used in a signal before its derivate is calculated.

\section{Application of a PID Controller with median filter to a Buck Converter}

Using a manual method, looking for optimize the Integral of the Square Error (ISE), a PID was tuned to control the DC/DC converter discussed at section 3.2, with a DC input of 12 V. A sample time of 0.05 microseconds was selected with a PWM Frequency of $250 \mathrm{KHz}$. The parameters calculated were $K_{p}=0.3$, $\mathrm{T}_{\mathrm{i}}=1 /\left(12 \times 10^{-6}\right)$ and $\mathrm{T}_{\mathrm{d}}=6 \times 10^{-6}$, see Figure 6 .

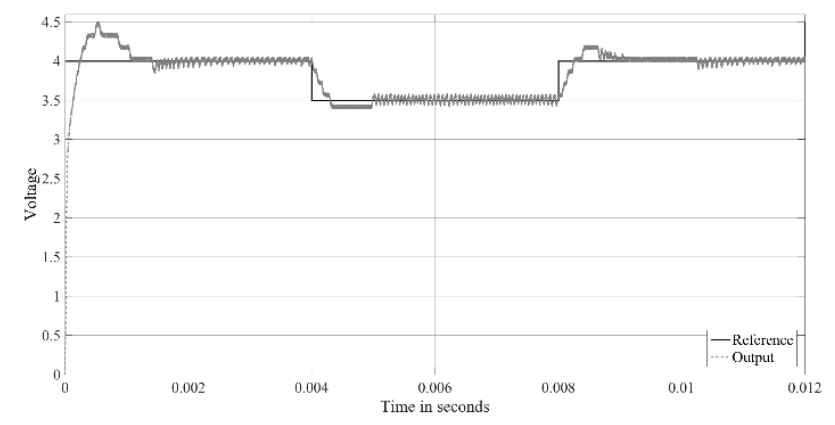

Figure 6 DC/DC Buck converter controlled by a PID

\section{FO Control of DC/DC buck Converter}

\section{Fractional Order PID Controller}

Podlubny (Podlubny, Dorcak, \& Kostial, 1997) (Podlubny, 1999) proposed the Fractional-Order $\mathrm{PI}^{\lambda} \mathrm{D}^{\delta}$ (FO-PID controller). In his proposal, the integrator $(\lambda)$ and the differentiator $(\delta)$ operator are real. Equation (10) shows the transfer function of this controller:

$$
C(s)=\frac{U(s)}{E(s)}=K_{p}+K_{i} s+K_{d} s
$$

where

$\lambda>0$, real integral operator

$\delta>0$, real differential operator
$\mathrm{K}_{\mathrm{p}}$, proportional constant

$\mathrm{K}_{\mathrm{i}}$, integration constant

$\mathrm{K}_{\mathrm{d}}$, differentiation constant.

The fractional-order controller internal configuration consists of the parallel connection of the proportional, integration, and derivative part (Goodwin, Graebe, \& Salgado, 2001) (Chopade, Khubalkar, Junghare, \& Aware, 2016).

In discrete time the controller has the form:

$$
C(z)=\frac{U(z)}{E(z)}=K_{p}+\frac{K_{i}}{\left(\left(z^{1}\right)\right)}+K_{d}\left(\left(z^{1}\right)\right)
$$

In both equations $(10,11)$ taking $\lambda=1$ and $\delta=1$, a classical PID controller is obtained. If $\lambda$ $=0$ and $\mathrm{K}_{\mathrm{i}}=0$, a $\mathrm{PD}^{\delta}$ controller is found. In summary, all these types of controllers are particular cases of the fractional-order controller, which is more flexible and gives an opportunity to better adjust the dynamical properties of a control system, (Monje, Chen, Vinagre, Xue, \& Feliu, 2010) (Petras, 2011).

\section{Application of a FO-PID Controller with median filter to a Buck Converter}

As in the case of PID Controller, a manual method, looking for optimize the Integral of the Square Error (ISE), was used to tune a FO-PID to control the $\mathrm{DC} / \mathrm{DC}$ converter discussed at section 3.2, with a DC input of $12 \mathrm{~V}$. A sample time of 0.05 microseconds was selected with a PWM Frequency of $250 \mathrm{KHz}$. The parameters calculated were $\mathrm{K}_{\mathrm{p}}=0.35, \quad \mathrm{~T}_{\mathrm{i}}=0.0025$, $\mathrm{T}_{\mathrm{d}}=0.0005, \lambda=0.9$ and $\delta=0.6$, see Figure 7 .

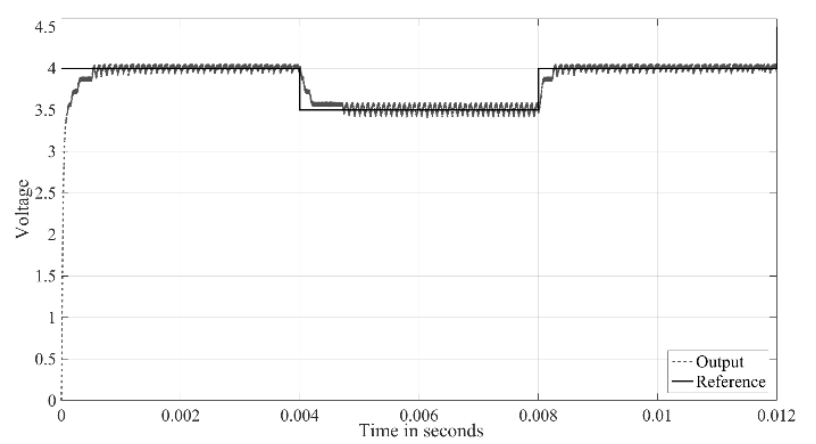

Figure 7 DC/DC Buck converter controlled by a FO-PID 
Figure 8 shows the ISE responses of the DC/DC Buck converter controlled by PID and FO-PID. As can be seen, the DC/DC Buck converter has a lower ISE when it is driven by the FO-PID.

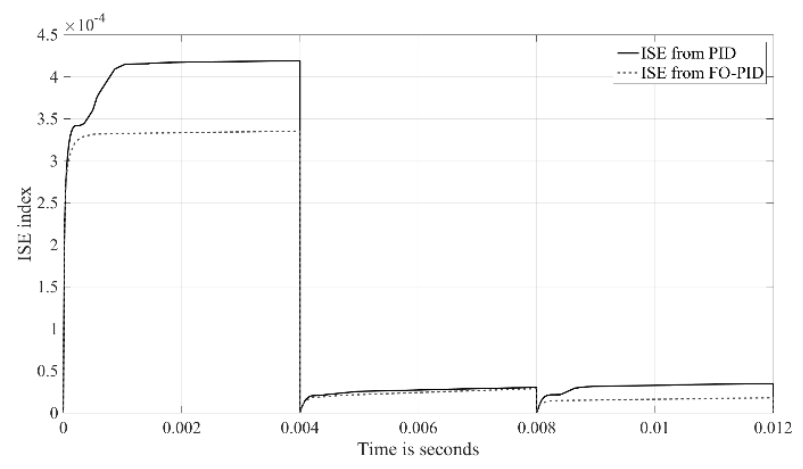

Figure 8 ISE responses of the DC/DC Buck converter controlled by PID and FO-PID

\section{Conclusions}

In this work, the operation of $\mathrm{DC} / \mathrm{DC}$ converters, specifically the Buck converter, has been described. Classical and hybrid modeling have shown a good accuracy, however the adaptability of the hybrid model has shown a better performance as compared with the circuit nonetheless its dependence on parameters selection. Classical and fractional order PID's were also discussed. Their performances, when they are regulating a DC/DC Buck converter were also showed. The ISE index analyses show that the fractional order PID offer a better performance as compared with the classical PID.

\section{Acknowledgments}

A. S. Damian-Mora would like to thank "Consejo Nacional de Ciencia y Tecnologia" for the economical support in her postgraduates studies. J. Ramirez-Espinoza would like to thank "Tecnologico Nacional de Mexico" for its support in his postgraduate studies.

\section{References}

Alternative Energy Institute, \& Smith, K. (2005). Power Our Future: An Energy Sourcebook for Sustainable Living. iUniverse, Inc.

Bacha, S., Munteanu, I., \& Bratcu, A. I. (2014). Power Electronic Converters Modeling and Control with Case Studies. London: Springer.
Bemporad, A., \& Morari, M. H. (1999). Control of systems integrating logic, dynamics, and constraints. Automatica , 35, 407-427.

Branicky, M. S., Borkar, V. S., \& Mitter, S. K. (1998). A unified framework for Hybrid Control: Model and Optimal control theory. IEEE Transactions on Automatic Control , 43, $31-45$.

Chopade, A. S., Khubalkar, S. W., Junghare, A. S., \& Aware, M. V. (2016). Fractional Order Speed Controller for Buck-Converter fed DC Motor. First International Conference on Control, Measurement and Instrumentation (CMI) (pp. 331-335). Jadavpur. India: IEEE.

Erickson, R. W., \& Maksimovic, D. (2004). Fundamentals of Power Electronics (2da ed.). Boulder, Colorado, USA: Kluwer Academic Publishers.

Gollu, A., \& Varaiya, P. (1989). Hybrid Dynamical Systems. 28th Conference on Decision and Control, (pp. 2708-2712). Tampa, Florida. USA.

Goodwin, G. C., Graebe, S. F., \& Salgado, M. E. (2001). Control system design. USA: Prentice Hall.

Hossain, M. Z., Rahim, N. A., \& Selvaraj, J. A. (2018). Recent progress and development on power DC-DC converter topology, control, design and applications: A review. Renewable and Sustainable Energy Reviews , 81, 205-230.

Kruger, P. (2006). Alternative Energy Resources: The Quest for Sustainable Energy (1a ed.). Wiley.

Monje, C. A., Chen, Y., Vinagre, B. M., Xue, D., \& Feliu, V. (2010). Fractional Order Systems and Controls: Fundamentals and Applications. (M. J. Johnson, Ed.) London, U.K.: Springer-Verlag.

Petras, I. (2011). Fractional-Order Nonlinear Systems: Modeling, Analysis and Simulation (First ed.). (A. C. Ibragimov, Ed.) Beijing, China: Springer.

Podlubny, I. (1999). Fractional-Order Systems and PILDu-Controllers. IEEE Transactions on Automatic Control , 44 (1), 208-214. 
Podlubny, I., Dorcak, L., \& Kostial, I. (1997). On Fractional Derivatives, Fractional-Order Dynamic Systems and PIIDu Controllers. Conference on Decision and Control (pp. 49854990). San Diego, USA: IEEE.

Witsenhausen, H. S. (1966). A Class of HybridState Continuous-Time dynamic systems. IEEE Transactions on Automatic Control , 11, 161167. 